\title{
Effects of Various Mouthwashes on the Orthodontic Nickel-Titanium Wires: Corrosion Analysis
}

\author{
Mehreen Wajahat ${ }^{1}$ \\ Faisal Moeen ${ }^{2}$ \\ Syed Wilayat Husain ${ }^{3}$ \\ Sumera Siddique ${ }^{4}$ \\ Zohaib Khurshid ${ }^{5}$
}

\author{
BDS \\ BDS, MSc \\ PhD \\ BDS, PhD \\ BDS, MRes, MDTFEd, FPFA
}

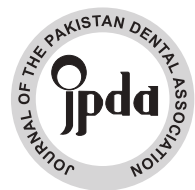

OBJECTIVES: This project was carried out to identify the least corrosive mouthwash when Nickel Titanium (NiTi) wires are employed in the oral environment for longer periods during the orthodontic treatment.

METHODOLOGY: Corrosion of NiTi archwires was investigated in different mouthwashes and artificial saliva. Artificial saliva was taken as a standard medium. A potentiodynamic test was performed using Gamry's potentiostat. This type of test comprises of a corrosion cell containing immersion medium, in which sample wire was dipped. A specified voltage was applied to complete electrochemical cell. Corrosion rate was calculated utilizing the Tafel equation through a software 'Echem analyst'. One-way ANOVA was conducted to compare the mean corrosion rates of wires immersed in different media. Field Emission Scanning Electron Microscope (FESEM) was used to analyze the surface characteristics of NiTi wires after the corrosion testing. RESULTS: NiTi wires tested in mouthwash containing $\mathrm{HCl}$ in $0.15 \% \mathrm{w} / \mathrm{v}$ of Benzydamine Hydrochloride (Enziclor ${ }^{\mathrm{TM}}$ ) produced greatest corrosion (16.2300+4.405 MPY). While Dexapanthenol + permethol containing mouthwash (Hi-Paraent ${ }^{\mathrm{TM}}$ ) showed minimum corrosion of the NiTi wires. The rate of corrosion was found to be insignificant in artificial saliva, the control medium. CONCLUSIONS: Research concludes that mouthwashes which contain dexapanthenol + permethol (e.g, Hi-Paradent ${ }^{\mathrm{TM}}$ ) are the safest most among those containing chlorhexidine gluconate + benzydamine hydrochloride(e.g, Enziclore $\left.{ }^{\mathrm{TM}}\right)$ and sodium monofluorophosphate (e.g, Secure ${ }^{\mathrm{TM}}$ ) in terms of corrosion of NiTi wires .

KEYWORDS: Corrosion; Orthodontic wires, Nickel-titanium wires, Potentiodynamic analysis, Mouthwashes

HOW TO CITE: Wajahat M, Moeen F, Husain SW, Siddique S, Khurshid Z. Effects of various mouthwashes on the orthodontic Nickel-Titanium wires: corrosion analysis. J Pak Dent Assoc 2020;29(1):30-37.

DOI: https://doi.org/10.25301/JPDA.291.30

Received: 01 August 2019, Accepted: 01 November 2019

\section{INTRODUCTION}

$\mathrm{L}$ iterature indicates that individuals with malaligned teeth are more prone to periodontal problems owing to the difficulty in accessing areas hence crowding of teeth creates hinderance in maintaining proper oral hygiene. ${ }^{1}$ Patients with such crowding who are more susceptible to dental caries might benefit from the additional

1. Lecturer + PGT, Department of Dental Materials, Islamic International Dental College.

2. Associate Professor, Department of Dental Materials, Islamic International Dental College.

3. Professor, Department of Material Science and Engineering, Institute of Space Technology.

4. Assistant Professor, Department of Physics and Astronomy, Texas Tech University, USA.

5. Lecturer, Department of Prosthodontics and Dental Implantology, College of Dentistry, King Faisal University, KSA.

Corresponding author: "Dr. Mehreen Wajahat" < mehrinwajahat09@gmail.com > use of fluoride mouth rinses in addition to regular brushing. ${ }^{2}$ Patients experiencing orthodontic treatment are prone to caries and periodontal disease since the presence of a fixed appliance may compromise the efficacy to maintain ideal oral cleanliness. There is some proof that an everyday use of fluoride mouthwash will decrease the danger of tooth decay and gum disease during treatment with fixed braces. ${ }^{3,4}$

The success of orthodontic treatment apart from other factors depends on the sliding mechanism between the wires and brackets. ${ }^{5}$ Corrosion of these wires owing to any stimulus increases friction. This friction provides higher resistance to sliding ${ }^{5-7}$ and can ultimately prolong the treatment duration. Nickel-titanium (NiTi) is one of the most commonly used wire materials in orthodontic treatment. Generally, these wires are considered corrosion resistant because of a protective passive film, titanium oxide $\left(\mathrm{TiO}_{2}\right)$ which is formed on these NiTi wires. This layer shields the wire from corrosion and 
other environmental effects. Corrosion may occur if this layer is compromised due to any factor which can create a reducing environment in the oral cavity.

After the placement of orthodontic appliances in the oral environment the occurrence of certain cases of stomatitis have been reported. ${ }^{8}$ A substantial number of proprietary products are available in the form of topical analgesics or antiseptic mouthwashes which contain active chemicals to reduce pain and soreness. These products also aim to prevent secondary infections associated with oral ulcers. ${ }^{9}$ Mouthwashes containing chlorhexidine gluconate have shown to reduce traumatic oral ulcers associated with the initial period of fixed appliance treatment. ${ }^{9}$ But the long term use of these mouthwashes can lead to a risk of corrosion in the orthodontic wires. The oral cavity is continuously bathed with saliva, which is a complex mixture of dissolved electrolytes with a high chloride content, as well as various organic substances. ${ }^{10}$ During the orthodontic treatment, wires are mechanically activated to achieve the required tooth movement. ${ }^{11}$ This relative movement of wires and the friction in the brackets may lead to the process of corrosion, for example, fretting corrosion. ${ }^{12}$ So, the mouthwashes prescribed and incorporated into the daily use of the patient during treatment with these mechanically activated orthodontic wires may initiate the process of corrosion.

In-vitro corrosion rate of frequently used NiTi archwires used for the orthodontic treatment was assessed and compared in variously prescribed mouthwashes in the patients with gingivitis. The basic purpose of this research was to select the least corrosive mouthwash that should be prescribed when patient is put on NiTi wires for longer durations during the orthodontic treatment.

\section{METHODOLOGY}

Nickel Titanium (NiTi) dental archwires (Ortho Organizer,USA) were tested. NiTi wires of the diameter $0.012 \mathrm{~mm}$ were selected based on their long term use in oral cavity during the first phase of orthodontic treatment. Three commonly used mouthwashes to treat gingivitis in the orthodontic patients were selected. Artificial saliva was selected as a control immersion medium. The wires to be

Table 1: List of testing materials

\begin{tabular}{|c|l|}
\hline Sample wire & Immersion Media/Electrolyte \\
\hline \multirow{4}{*}{$\mathrm{NiTi}$} & Artificial saliva \\
\cline { 2 - 2 } & Enziclor $^{T M}$ \\
\cline { 2 - 2 } & Secure $^{T M}$ \\
\cline { 2 - 2 } & Hi-Paradent $^{T M}$ \\
\hline
\end{tabular}

tested were made non-conducting with an epoxy resin coating, leaving behind $2 \mathrm{~cm}$ of the wire which was to be dipped in the electrolyte (immersion media). After overnight drying, the wires were cleaned with ethanol followed by a step which involved washing with distilled water.

Table 2: Composition of Mouthwashes

\begin{tabular}{|c|c|c|}
\hline $\begin{array}{c}\text { Serial } \\
\text { No. }\end{array}$ & $\begin{array}{c}\text { Mouthwash } \\
\text { (electrolyte) }\end{array}$ & Composition \\
\hline 1. & Enziclor* $^{*}$ & $\begin{array}{c}\text { Chlorhexidine gluconate }(0.2 \% \mathrm{w} / \mathrm{v}) \\
\text { Benzydamine hydrochloride }(0.15 \% \mathrm{w} / \mathrm{v})\end{array}$ \\
\hline 2. & Secure $^{*}$ & $\begin{array}{c}\text { Sodium monofluorophosphate } \\
(0.05 \% \mathrm{w} / \mathrm{v})\end{array}$ \\
\hline 3. & Hi-Paradent & $\begin{array}{c}\text { Dexpanthenol }(0.5 \% \mathrm{w} / \mathrm{v}) \\
\text { Permethol }(0.1 \% \mathrm{w} / \mathrm{v})\end{array}$ \\
\hline
\end{tabular}

*Platinum Pharmaceuticals

NiTi archwires manufactured by Ortho Organizer, USA were utilized in this study. Energy Dispersive Spectroscopy (EDS) of as-received arch wire was carried out showing the composition of $\mathrm{NiTi}$ arch wires. Although NiTi is known to be equiatomic alloy (having equal amounts of Nickel and Titanium), some other elements were also found to be added.

\begin{tabular}{l|ll}
\hline Element & Weight $\%$ & Atomic\% \\
OK & 4.08 & 12.33 \\
AIK & 0.38 & 0.69 \\
TiK & 44.02 & 44.49 \\
NiK & 51.52 & 42.48 \\
& & \\
Totals & 100.00 & \\
\hline
\end{tabular}

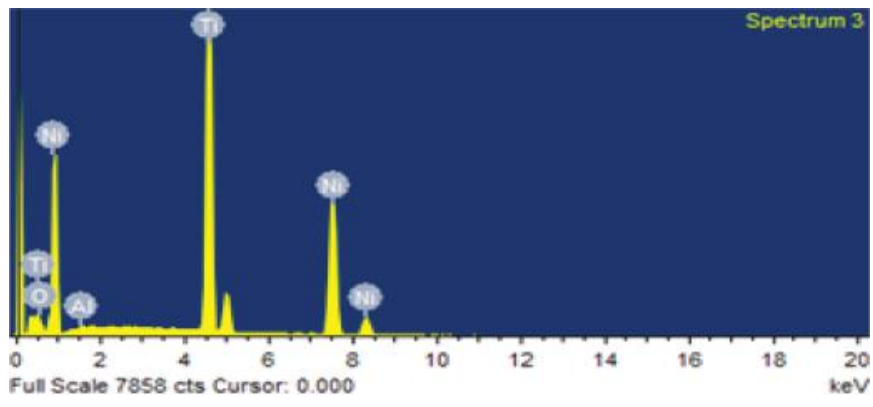

\section{PREPARATION OF ARTIFICIAL SALIVA}

A mineral medium with a composition similar to saliva was prepared as described by Levallois et al. ${ }^{13} 700 \mathrm{ml}$ of distilled water was poured into a $1000 \mathrm{ml}$ glass beaker and this was stirred using a magnetic bar at $37^{\circ} \mathrm{C}$. After each 
preceding reagent had completely dissolved, a new reagent was added. Reagents were dissolved in distilled water in the sequence listed in table- 3 .

Geigy in 1972 showed that its composition was very close to saliva. Hydrogen carbonate utilized in the preparation of this medium is known for its buffering effects which are close to that of real in-mouth conditions of saliva. Phosphates

Table 3: List of Reagents (composition) of the artificial saliva $(\mathrm{pH}=6.9)$.

\begin{tabular}{|c|c|}
\hline Compound & Concentration $(\mathrm{mg} / \mathrm{L})$ \\
\hline $\mathrm{NaCl}$ & 125.64 \\
\hline $\mathrm{KCl}$ & 963.90 \\
\hline $\mathrm{KSCN}$ & 189.20 \\
\hline $\mathrm{KH}_{2} \mathrm{PO}_{4}$ & 654.50 \\
\hline $\mathrm{CO}\left(\mathrm{NH}_{2}\right)_{2}$ & 200.00 \\
\hline $\mathrm{CaCl}_{2} .2 \mathrm{H}_{2} \mathrm{O}$ & 227.80 \\
\hline $\mathrm{Na}_{2} \mathrm{SO}_{4} 10 \mathrm{H}_{2} \mathrm{O}$ & 763.20 \\
\hline $\mathrm{NH}_{4} \mathrm{Cl}$ & 178.00 \\
\hline $\mathrm{NaHCO}_{3}$ & 630.80 \\
\hline
\end{tabular}

contributed to maintaining the $\mathrm{pH}$ value as close to neutrality as possible. Mineralization was also achieved by the addition of phosphates and calcium. ${ }^{13}$

\section{POTENTIODYNAMIC TESTING}

A potentiostat (R-600, Gamry instruments) was used to perform the potentiodynamic tests for corrosion analysis. All the test wires utilized were under no mechanical deformation during the corrosion tests. Prepared wires were dipped into the electrolyte (Immersion media) for 2-3 hours to stabilize the potential prior to starting the experiment. Metal alloys are immersed in solution in which they are to be tested so that a stable open circuit potential (OCP) can be attained before starting the polarisation scan. OCP measurements indicated that the OCP of the alloy at 3 hours was almost identical to OCP measured at several hours, depicting that once a potential is attained, it can be considered as constant because there is no effect of varying dipping time of sample in solution. Dipping for more than 2-3 hours should however be avoided. Therefore this dipping time ( $\mathrm{t}=2-3 \mathrm{hrs})$ was approved as the time requisite to get a stabilization for all the electrochemical measurements so as to avoid addition of any misleading values of already existing potential when potential is applied for the experiment. ${ }^{14}$ Sample wire was used as a working electrode. A saturated calomel electrode (SCE) was used as the reference electrode whereas a graphite rod was used as a counter electrode. The potentiodynamic polarization curves were obtained from - $500 \mathrm{mV}$ toward the anodic direction, with a scan rate of
$1 \mathrm{mV} / \mathrm{s}$ and a final voltage of $1500 \mathrm{mV}$. Corrosion resistance parameters, including the corrosion potential (at this potential the sum of the anodic and cathodic reaction rates on the electrode surface is zero) and the corrosion rate (Icorr; the anodic current density at the potential of Ecorr), were obtained from these potentiodynamic polarization curves. The surface of the NiTi wire after corrosion testing was observed using a Field Emission Scanning Electron Microscope (FESEM) (mira TESCAN). One-way ANOVA was conducted to compare the mean corrosion rates between NiTi wires immersed in the different media using SPSS-23. The inter-group corrosion rates between the four solutions was compared using the post-hoc Tukey analysis.

\section{RESULTS}

Potentiodynamic polarization curves of the NiTi wires in artificial saliva and three types of mouthwashes revealed an active-to-passive transition behavior in the polarization curves. Representative potentiodynamic polarization curves of NiTi wires in different immersion media are given below (Figure 1).

In Figure 1, represents series of potentiodynamic polarization curves, the cathodic section (passive region i.e., from $0.5 \mathrm{~V}$ to $0.4 \mathrm{~V}$, for standard solution) of these polarization

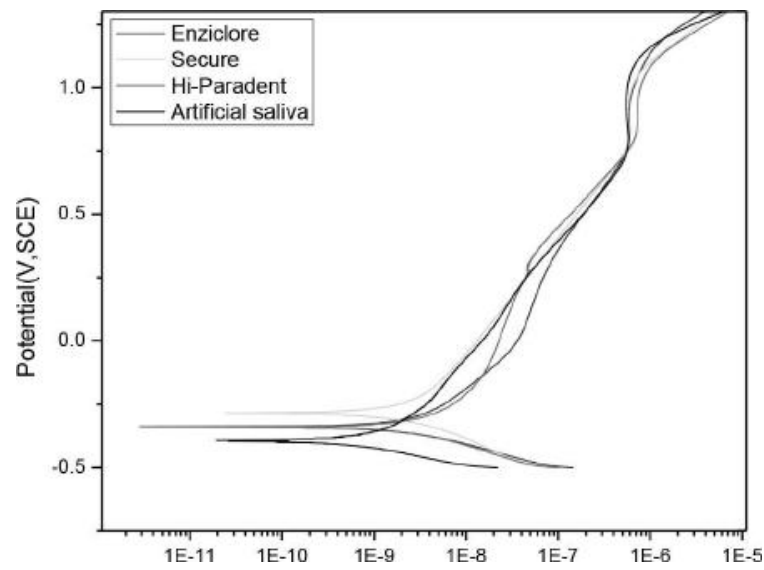

Figure 1: Potentiodynamic polarization curves of NiTi wires in chlorhexidine gluconate + Benzydamine Hydrochloride mouthwash (Enziclor $\left.{ }^{T M}\right)$, Sodium Monofluorophosphate (Secure ${ }^{T M}$ ) and Dexapanthenol + permethol $\left(H i\right.$-Paradent $\left.{ }^{T M}\right)$. ( $\mathrm{x}$-axis is in logarithimic scale)

curves shows no vertical stage and consists only of one smooth slope. After cathodic stage anodic stage (active region i.e., from $0.4 \mathrm{~V}$ to $1.3 \mathrm{~V}$ ) starts. The corrosion potentials of sample wires in four test solutions were close to each other with small peaks in anodic current. The current density was found to be lowest in artificial saliva i.e. $6.900 \mathrm{nA} / \mathrm{cm}^{2}$. Among the mouthwashes lowest current density was found in $\mathrm{Hi}$-Paradent ${ }^{T M}$ i.e., $8.200 \mathrm{nA} / \mathrm{cm}^{2}$. Lowest current density 
Table 4: Corrosion Parameters

\begin{tabular}{|c|c|c|c|c|}
\hline Sample (Wire) & $\begin{array}{c}\text { Immersion } \\
\text { media }\end{array}$ & $\mathrm{E}_{\text {corr }}(\mathrm{mV})$ & $I_{\text {carr }}\left(\mathrm{nA} / \mathrm{cm}^{2}\right)$ & $\begin{array}{c}\text { Corrosion rate } \\
\text { (MPY) }\end{array}$ \\
\hline & Artificial saliva & -420 & 11.50 & $6.100 \times 10^{-3}(0.0061)$ \\
\hline & & -397 & 6.900 & $3.654 \times 10^{-3}(0.003654)$ \\
\hline & & -405 & 7.800 & $4.132 \times 10^{-3}(0.004132)$ \\
\hline & & -257 & 10.20 & $5.383 \times 10^{-3}(0.005383)$ \\
\hline & & -252 & 10.90 & $5.790 \times 10^{-3}(0.00579)$ \\
\hline & & -301 & 16.90 & $8.837 \times 10^{-3}(0.008837)$ \\
\hline \multirow{18}{*}{$\mathrm{NiTi}$} & \multirow[t]{6}{*}{ Enziclor ${ }^{T M}$} & -305 & 27.70 & $14.67 \times 10^{-3}(0.01467)$ \\
\hline & & -277 & 26.80 & $14.16 \times 10^{-3}(0.01416)$ \\
\hline & & -351 & 11.70 & $12.37 \times 10^{-3}(0.01237)$ \\
\hline & & -374 & 15.40 & $16.29 \times 10^{-3}(0.01629)$ \\
\hline & & -397 & 14.10 & $14.91 \times 10^{-3}(0.01491)$ \\
\hline & & -364 & 23.60 & $24.98 \times 10^{-3}(0.02498)$ \\
\hline & \multirow[t]{6}{*}{ Secure ${ }^{T M}$} & -207 & 18.1 & $9.57 \times 10^{-3}(0.00957)$ \\
\hline & & -280 & 20.30 & $10.37 \times 10^{-3}(0.01037)$ \\
\hline & & -373 & 33.7 & $17.82 \times 10^{-3}(0.01782)$ \\
\hline & & -12.40 & 12.30 & $12.98 \times 10^{-3}(0.01298)$ \\
\hline & & -284 & 17.90 & $18.88 \times 10^{-3}(0.01888)$ \\
\hline & & -347 & 12.10 & $12.75 \times 10^{-3}(0.01275)$ \\
\hline & \multirow{6}{*}{ Hi-Paradent ${ }^{T M}$} & -206 & 11.40 & $6.027 \times 10-3(0.006027)$ \\
\hline & & -258 & 9.89 & $5.239 \times 10^{-3}(0.005239)$ \\
\hline & & -296 & 8.200 & $4.341 \times 10^{-3}(0.004341)$ \\
\hline & & -268 & 13.50 & $14.24 \times 10^{-3}(0.01424)$ \\
\hline & & -335 & 9.650 & $10.19 \times 10^{-3}(0.01019)$ \\
\hline & & -357 & 9.250 & $9.770 \times 10^{-3}(0.00977)$ \\
\hline
\end{tabular}

Ecorr=Corrosion potential, Icor=Current density, MPY=Mills Per Year. Potentiodynamic test of NiTi in Enziclor mouthwash has given maximum value of corrosion rate i.e, 0.02498 MPY whereas minimum value of corrosion rate among tested mouthwashes was obtained in Hi-Paradent i.e. 0.004341 MPY.

density represents lowest corrosion rate. The curve having more fluctuations in anodic section had more pitting effect e.g, the curve of Enziclore test (Blue in Fig 1) has more fluctuations as compared to the curve of Secure (Green in Figure 1) which had intermediate fluctuations. Hi-Paradent (Red in Fig 1) showed lowest fluctuations of potentiodynamic curve representing lowest corrosion rate. This figure shows a comparison of representative values in each immersion medium. All the other values of corrosion parameters i.e., Ecorr, Icorr and corrosion rates calculated from potentiodynamic polarization curves of all the samples in various media one by one are given in Table- 4 .

\section{STATISTICAL ANALYSIS}

One way ANOVA showed that there was no difference in the corrosion rates among NiTi wires immersed in the 3 types of mouthwash $(\mathrm{p}<0.001)$. Mean Corrosion Rate for Nickel Titanium $(\mathrm{NiTi})=10.9772+5.4594$.

Basically an ANOVA test and s post-hoc Tukey analysis was conducted to compare the intergroup differences in the corrosion rates between the 4 different solutions. In the Table 5 , the descending order of the corrosion rates is as follows: Enziclor $^{T M}$, Secure ${ }^{T M}$, Hi-Paradent ${ }^{T M}$, Artificial saliva.
Table 6 illustrates the inter-group corrosion rates. These solutions can be placed in two groups (Enziclor ${ }^{T M}$ with Secure $^{T M}$ and Hi-Paradent ${ }^{T M}$ with Artificial Saliva). Means, both Enziclor ${ }^{T M}$ and Secure ${ }^{T M}$ have statistically different (higher) corrosion rates from both Hi-Paradent ${ }^{T M}$ and Artificial Saliva.

Table 5: Corrosion Rates of NiTi Wires as Per Different Immersion Media.

\begin{tabular}{|c|c|c|}
\hline Immersion Media & $\begin{array}{c}\text { Mean Corrosion Rate } \\
\text { (MPY X 10 } 10^{-3}\end{array}$ & $\begin{array}{c}\text { Standard Deviation } \\
\text { (MPY X 10 }\end{array}$ \\
\hline Artificial Saliva $^{-3}$ & 5.6493 & 1.8297 \\
Enziclor $^{T M}$ & 16.2300 & 4.4705 \\
\hline Hi-Paradent $^{\mathrm{TM}}$ & 8.3012 & 3.7743 \\
Secure $^{\mathrm{MM}}$ & 13.7283 & 3.8306 \\
\hline
\end{tabular}

However, there is no difference in the corrosion rates between Enziclor ${ }^{T M}$ and Secure ${ }^{T M}$. Also, it holds true vice versa.

Table 6: Comparison of the Corrosion rates of NiTi Wires Per Immersion Media.

\begin{tabular}{|c|c|c|c|}
\hline $\begin{array}{c}\text { Immersion } \\
\text { Media }\end{array}$ & Comparison Media & $\begin{array}{c}\text { Mean Difference } \\
(\text { MPY X 10 10 }\end{array}$ & P Value \\
\hline \multirow[t]{2}{*}{ Enziclor $^{T M}$} & Secure $^{\mathrm{M}}$ & $2.5017 \pm 2.0867$ & 0.635 \\
\hline & $\begin{array}{l}\text { Hi-Paradent }{ }^{\text {IM }} \\
\text { Artificial Saliva }\end{array}$ & $\begin{array}{c}7.9288 \pm 2.0867 \\
10.5807 \pm 2.0867\end{array}$ & $\begin{array}{c}0.006 \\
<0.001\end{array}$ \\
\hline \multirow{2}{*}{ Secure $^{T M}$} & Hi-Paradent ${ }^{\mathrm{TM}}$ & $8.0790 \pm 2.0867$ & 0.005 \\
\hline & Artificial Saliva & $5.4272 \pm 2.0867$ & 0.074 \\
\hline Hi-Paradent ${ }^{T M}$ & Artificial Saliva & $2.6518 \pm 2.0867$ & 0.591 \\
\hline
\end{tabular}

That is, both $\mathrm{Hi}$-Paradent ${ }^{T M}$ and Artificial Saliva have statistically lower corrosion rates than Enziclor ${ }^{T M}$ and Secure $^{T M}$. There is no statistical difference between the corrosion rates of Hi-Paradent ${ }^{T M}$ and Artificial Saliva. The inter-group differences between the four different solutions have been illustrated in table 6 .

As shown, Enziclor ${ }^{T M}$ has significantly greater corrosion rates than both Hi-Paradent ${ }^{T M}(\mathrm{p}=0.006)$ and Artificial Saliva ( $\mathrm{p}<0.001)$. Also, Secure ${ }^{T M}$ has a significantly higher corrosion rate than both Hi-Paradent ${ }^{T M}(\mathrm{p}=0.005)$ and Artificial Saliva $(\mathrm{p}=0.074)$.

\section{SURFACE ANALYSIS}

FESEM images showed the surface irregularities and small pits in the wires tested in Enziclor ${ }^{\mathrm{TM}}$, confirming the corrosion in this media.

The literature showed that the surface defects produced during the manufacturing process of NiTi alloy can cause corrosion. ${ }^{15}$ Oshida et al. also reported the possibility of corrosion on the sites of surface defects created during fabrication. ${ }^{16}$ Localized corrosion on the NiTi surfaces can be enhanced due to the surface defects. ${ }^{17}$

$\mathrm{NiTi}$ wires showed the maximum corrosion resistance in $\mathrm{Hi}$-Paradent ${ }^{T M}$ and the highest vulnerability to corrosion 

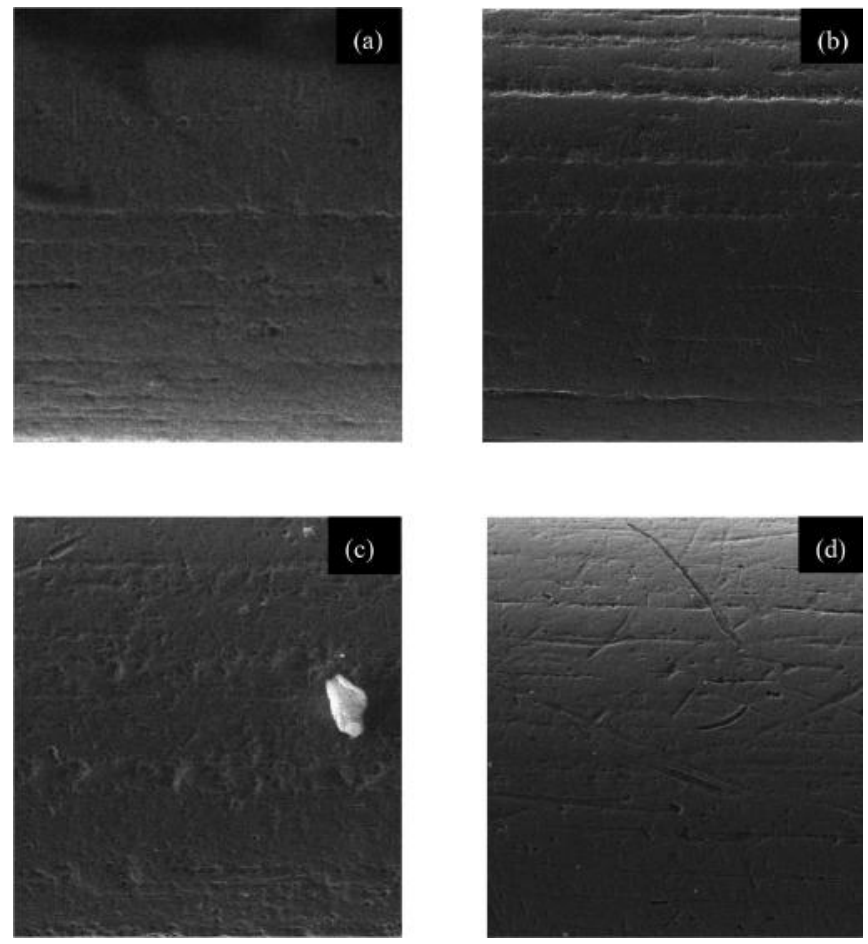

Figure 2: The SEM observations ( Mag $1.00 \mathrm{kx}$ ) of the tested NiTi wires after potentiodynamic tests in Artificial saliva, Hi-Paradent ${ }^{T M}$, Secure $^{T M}$ and Enziclor ${ }^{T M}$ (a-d)

Table 7: $\mathrm{pH}$ of test solutions

\begin{tabular}{|c|c|c|}
\hline Immersion media & pH meter & pH strips \\
\hline Artificial saliva & 6.9 & $6-7$ \\
\hline Hi-Paradent $^{T M}$ & 4.89 & $4-5$ \\
\hline Secure $^{T M}$ & 4.82 & $4-5$ \\
\hline Enziclor $^{T M}$ & 4.5 & $4-5$ \\
\hline
\end{tabular}

in Enziclor ${ }^{T M}$ mouthwash. It can be linked to the $\mathrm{pH}$ of media provided other factors are kept at constant. Lower or more acidic mouthwashes are hence more corrosive. This feature decreases as $\mathrm{pH}$ of the media increases or moves to alkalinity. The decreasing trend of corrosion is exactly in accordance with the increase in $\mathrm{pH}$ of media, as shown in Table 7.

\section{DISCUSSION}

Electrochemical nature of the oral cavity must be understood to know the process of corrosion in the oral cavity. Literature establishes that the leading features for an environment to be corrosive include oxidation potential (Pourbaix, 1973) and an inconstant presence of oxygen and hydrogen. ${ }^{18}$ In the oral cavity, anaerobic bacteria are present which make a range in the pressures of oxygen and hydrogen possible. Variable amounts of oxygen and hydrogen give rise to either oxidation or reduction in the oral cavity. Factors that will provide oxidation environment are considered to be least corrosive and vice versa. Therefore, mouthwashes whose chemicals tend to take away oxygen atoms from the outermost protective layer of NiTi lead to the breakdown of this passive film initiating corrosion of the underlying wire.

According to Ewers and Greener, the range of oxidation potential (the potential at which oxidation occurs) present in the oral cavity ranges from -58 to $+212 \mathrm{mV}$ relative to saturated calomel electrode (SCE) suggesting that the wires are not susceptible to corrosion normally. ${ }^{19}$ Therefore, artificial saliva was utilized as a control medium in this study. Results clearly showed the minimum rate of corrosion in this media i.e, $5.6493+1.8297$. There was no difference observed in the rates of corrosion in the $\mathrm{NiTi}$ wires immersed in artificial saliva $(\mathrm{p}=1.00)$ proving that NiTi wires were impervious to corrosion in articial saliva.

The study by Kim and Johnson showed that the characterization of NiTi wires reveal extensive pitting and localized corrosion after potentiodynamic polarization tests in $0.9 \% \mathrm{NaCl}$ solution. In the case of clinical implications, the use of different chemicals in the form of mouthwashes may lead to pitting corrosion on the wires, causing increased friction. ${ }^{20}$ In the present study pitting corrosion was observed on the surfaces of tested samples under FESEM (Figure 2d). Fretting corrosion (corrosion due to the motion of two mating surfaces against each other) was not seen in tested samples because fretting is a type of wear and this experiment was carried out in a static controlled setup. Apart from pits, long wedges were also observed on surfaces of tested wires. This was due to cold rolling, which is the processing of alloy into wires. Due to cold rolling, grains arrange along specific lines (rolling direction). These regions are susceptible to corrosion so the lengthy wedges were observed in FESEM images.

In the present study, as the chemical assembly of protective film on all NiTi wires is identical, omprising mainly of $\mathrm{TiO}_{2}$ with lesser amounts of $\mathrm{NiO}$, but corrosion of wires did occur. Statistical analysis showed a significant difference in the corrosion rates among the NiTi wires tested in different mouthwashes $(\mathrm{p}<0.001)$. The trend of corrosion of the NiTi wires in different immersion media established from this study can be summarized as:

\section{Enziclor $^{\mathrm{TM}}>$ Secure $^{\mathrm{TM}}>$ Hi-Paradent ${ }^{\mathrm{TM}}>$ Artificial Saliva}

This trend is exactly opposite to $\mathrm{pH}$ of immersion media. Therefore corrosion and $\mathrm{pH}$ can be called inversely proportional to each other. If all the other factors remain constant, the $\mathrm{pH}$ of the immersion media can help explain the corrosion trends observed in reverse order. The lower the $\mathrm{pH}$ of the media, the greater the corrosion rate. In other words, as the immersion media becomes more acidic, the 
corrosion tendency increases, and the corrosion resistance of the archwire decreases. For the present study, Enziclor ${ }^{T M}$ had the least $\mathrm{pH}$ (Table 7). As a result, the NiTi wires exposed to Enziclor ${ }^{T M}$ displayed the greatest corrosion rate. As the acidity decreased and the alkalinity increased, the corrosion rate decreases as well.

Corrosion occurs in different environments i.e, air, water, acids and chorus environment etc. However behavior is different in different environments. In the present study ingredients of immersion media caused and accelerated corrosion process. Acidic $\mathrm{pH}$ may dissolve the surface oxide films and avoids its reorganization thereby enhancing corrosion. ${ }^{21}$ Based on the results of this research, Enziclor ${ }^{T M}$ mouthwash produced substantial amounts of corrosion $(16.2300+4.4705 \mathrm{MPY})$ in the NiTi wires as compared to the other mouthwashes. According to a study on 'Surface characterizations and corrosion resistance of nickel-titanium orthodontic archwires in artificial saliva of various degrees of acidity,' a decrease in $\mathrm{pH}$ of the electrolyte leads to a rise in the values of Ecorr and Icorr. Decreasing $\mathrm{pH}$ gives rise to an increase in the concentration of $\mathrm{H}+$; as a consequence, it will increase the cathodic reaction $2 \mathrm{H}++2 \mathrm{e}-\longrightarrow \mathrm{H}_{2}$ on the NiTi wire. Therefore, the reaction at anode causes the metal to dissolve and this hastens the delivery of electrons for the cathodic reaction at the potential of Ecorr. The values of Ecorr and Icorr were amplified (mixed-potential theory). ${ }^{22}$ In the present case, Enziclor ${ }^{T M}$ has the lowest $\mathrm{pH}$ because of an acidic component in its formulation. Consequently, Ecorr and Icorr values were higher in this medium leading to an increased rate of corrosion as compared to others. So, the cause of highest rate of corrosion in this medium ows to acidic $\mathrm{pH}$ and the presence of $\mathrm{HCl}$ in its composition (i.e, Chlorhexidine gluconate + Benzydamine $\mathrm{HCl}$ ). This $\mathrm{HCl}$ breaks down increasing the concentration of hydrogen ions in this medium, leading to further increase in dissolution of metal. The anodic region in the polarization curves of wires was as a result of localized or pitting corrosion and not due to the uniform corrosion.

Fluoridated mouthwash could also create acidic environment. ${ }^{21}$ Mean corrosion rate in Secure ${ }^{T M}$ (Fluoride containing) mouthwash was observed as $13.7283+3.8306$. Mean corrosion rate of the NiTi wires in $\mathrm{Hi}$-paradent ${ }^{T M}$ medium was found to be $8.3012+3.7743$, which is minimum among all mouthwashes utilized in this study. The passive film on the NiTi wires provided a maximum resistance to ion-transfer in medium, making this medium least corrosive during the treatment with NiTi wires. From the discussion above it can be inferred that passive film constancy of NiTi wire in $\mathrm{Hi}$-Paradent ${ }^{T M}$ immersion medium was maximum, providing an utmost shield in this medium from corrosion.

The biocompatibility of any metal is linked mostly to the passive film on the surface of that metal. AES surface-depth profile analysis suggests that the amount of Nickel oxide on the surface of NiTi wires is lower as compared to Titanium oxide $\left(\mathrm{TiO}_{2}\right){ }^{23-25}$ This Titanium oxide $\left(\mathrm{TiO}_{2}\right)$ can provide good biocompatibility of the NiTi alloy. ${ }^{23,24}$ Corrosion of NiTi leads to biologically negative effects. ${ }^{23,26-28}$ Sample wires showed low values of Icorr and immunity to pitting corrosion in the artificial saliva. The difference in the rates of corrosion between the following mouthwashes was found to be significant (Significant P values): -

1. Enziclor ${ }^{T M}$ and $H i$-Paradent ${ }^{T M}$

2. Enziclor ${ }^{T M}$ and Artificial Saliva

3. Secure $^{T M}$ and Hi-Paradent ${ }^{T M}$

As corrosion of these archwires can also be calculated with the individual chemicals present in these mouthwashes to assess the behaviour of different chemicals with different wires.

However further room of research exists in:-

a. Evaluation of the amount of nickel released after corrosion in the case of various mouthwashes (to avoid nickel allergy in patients with nickel hypersensitivity).

b. Evaluation of the effects of corrosion on American manufactured versus Chinese manufactured archwires using different mouthwashes.

c. Evaluation of the corrosion rate of archwires in various beverages (tea, coffee and acidic drinks).

d. Corrosion analysis of mechanically bent wires (as bends or curves manually placed in the SS wires by the dentist may become a target spot for corrosion).

\section{CONCLUSIONS}

Corrosion rate basically states, 'rate of corrosion in Mills Per Year' (1Mill=One 1000th of an inch) i.e, values of corrosion rate obtained convey the extent to which that specific mouthwash will cause corrosion in the wire in a year if repeatedly exposed to it whereas, the treatment time of orthodontic archwires (especially NiTi) inside the oral cavity is less than a year. But this is compensated in natural environment as young orthodontic patients frequently take acidic drinks which may add to the effects of corrosion. Hence effects of corrosion which are obtained in a year's period may practically be seen before the completion of one year in the oral cavity where the patient is not using mouthwash alone but taking other foods and drinks as well.

It can therefore be concluded that when the NiTi wire is used for longer periods during the orthodontic treatment, Secure $^{T M}$ and Hi-Paradent ${ }^{T M}$ mouthwashes should be preferably recommended for treating gingival problems to ensure frictionless tooth movement as a result of minimum 
corrosion. Enziclor ${ }^{T M}$ should be avoided in such cases owing to its corrosive effects on NiTi wires.

Author Contributions: Conceptualization, Mehreen Wajahat; Formal analysis, Sumera Siddique; Methodology, Mehreen Wajahat; Project administration, Faisal Moeen; Resources, Syed Wilayat Husain; Supervision, Faisal Moeen and Syed Wilayat Husain; Validation, Syed Wilayat Husain; Writing - original draft, Mehreen Wajahat; Writing - review \& editing, Zohaib Khurshid.

Funding: "This research received no external funding" Acknowledgements: The author acknowledges the core backing of this research work to the team at the Institute of space technology especially Mr. Tahir, Engr. Abdul Moeez and Mr. Ahsan. The author is also very thankful to the team at the IRCBM COMSATS for their great cooperation. Dr Abdul Samad and Dr Akif Anwar are the names worth mentioning. Dr Sundus Iftikhar and Dr Tania Siddiqui were also very helpful.

\section{CONFLICTS OF INTEREST}

The authors declare no conflict of interest.

\section{REFERENCES}

1. Khoroushi M, Kachuie M. Prevention and treatment of white spot lesions in orthodontic patients. Contemp Clin Dentis. 2017;8:11. https://doi.org/10.4103/ccd.ccd_216_17

2. Ellwood R, Cury J. How much toothpaste should a child under the age of 6 years use? Europ Archives Paediatr Dentis. 2009;10:168-74. https://doi.org/10.1007/BF03262679

3. Benson PE, Parkin N, Millett DT, Dyer F, Vine S, Shah A. Fluorides for the prevention of white spots on teeth during fixed brace treatment. Cochrane Database of Systematic Reviews. 2004.

https://doi.org/10.1002/14651858.CD003809.pub2

4. Alzoubi EEM, Borg VT, Gatt G, Aguis AM, Attard N. The importance of oral health education in patients receiving orthodontic treatment. J Oral Res Rev. 2019;11:12.

https://doi.org/10.4103/jorr.jorr_24_18

5. Griffiths HS, Sherriff M, Ireland AJ. Resistance to sliding with 3 types of elastomeric modules. Am J Orthod Dentofac Orthop. 2005; 127:670-75.

https://doi.org/10.1016/j.ajodo.2004.01.025

6. Henao SP, Kusy RP. Evaluation of the frictional resistance of conventional and self-ligating bracket designs using standardized archwires and dental typodonts. Angle Orthod. 2004;74:202-11.

7. Tselepis M, Brockhurst P, West VC. The dynamnic frictional resistance between orthodontic brackets and arch wires. Am J Orthod
Dentofac Orthop. 1994;106:131-38.

https://doi.org/10.1016/S0889-5406(94)70030-3

8. Jensen CS, Menné T, Duus Johansen J. Systemic contact dermatitis after oral exposure to nickel: a review with a modified meta-analysis. Contact dermatitis. 2006;54:79-86.

https://doi.org/10.1111/j.0105-1873.2006.00773.x

9. Asher C, Shaw W. Benzydamine hydrochloride in the treatment of ulceration associated with recently placed fixed orthodontic appliances. Europ J Orthod. 1986;8:61-4.

https://doi.org/10.1093/ejo/8.1.61

10. Joseph A, editor Corrosion of orthodontic devices. Seminars in orthodontics; 1997: Elsevier.

11. Grimsdottir MR, Gjerdet NR, Hensten-Pettersen A. Composition and in vitro corrosion of orthodontic appliances. Am J Orthod Dentofac Orthope. 1992;101:525-32.

https://doi.org/10.1016/0889-5406(92)70127-V

12. Merritt K, Brown SA. Metal sensitivity reactions to orthopedic implants. Int J dermatol. 1981;20:89-94. https://doi.org/10.1111/j.1365-4362.1981.tb00408.x

13. Levallois B, Fovet Y, Lapeyre L, Gal JY. In vitro fluoride release from restorative materials in water versus artificial saliva medium (SAGF). Dental Materials. 1998;14:441-47. https://doi.org/10.1016/S0300-5712(99)00019-6

14. Zaid B, Saidi D, Benzaid A, Hadji S. Effects of $\mathrm{pH}$ and chloride concentration on pitting corrosion of AA6061 aluminum alloy. Corrosion Science. 2008;50:1841-7.

https://doi.org/10.1016/j.corsci.2008.03.006

15. Schwaninger B, Sarkar NK, Foster BE. Effect of long-term immersion corrosion on the flexural properties of nitinol. Am J orthod. 1982;82:45-9.

https://doi.org/10.1016/0002-9416(82)90545-0

16. Oshida Y, Sachdeva RC, Miyazaku S. Microanalytical characterization and surface modification of TiNi orthodontic archwires. Bio-medical materials and engineering.1992;2:51-69.

https://doi.org/10.3233/BME-1992-2201

17. Abiko Y. Effects of NiTi surface texture on corrosion resistance and cellular response. J Jpn Soc Dent Products. 1996;9:9-17.

18. Becking LB, Kaplan IR, Moore D. Limits of the natural environment in terms of $\mathrm{pH}$ and oxidation-reduction potentials. J Geology. 1960;68:243-84.

https://doi.org/10.1086/626659

19. Ewers G, Greener E. The electrochemical activity of the oral cavitya new approach. J Oral Rehabil. 1985;12:469-76.

https://doi.org/10.1111/j.1365-2842.1985.tb01293.x

20. Kim H, Johnson JW. Corrosion of stainless steel, nickel-titanium, coated nickel-titanium, and titanium orthodontic wires. The Angle Orthod. 1999;69:39-44. 
21. Pataijindachote J, Juntavee N, Viwattanatipa N. Corrosion Analysis of Orthodontic Wires: An Interaction Study of Wire Type, pH and Immersion Time. Adv Dent \&amp; Oral Health. 2018;10(1): 555780 .

https://doi.org/10.19080/ADOH.2018.10.555780

22. Wever D, Veldhuizen A, De Vries J, Busscher H, Uges D, Van Horn J. Electrochemical and surface characterization of a nickeltitanium alloy. Biomaterials. 1998;19:761-69.

https://doi.org/10.1016/S0142-9612(97)00210-X

23. Shabalovskaya SA, Anderegg JW. Surface spectroscopic characterization of TiNi nearly equiatomic shape memory alloys for implants. J Vacuum Sci Technol A: Vacuum, Surfaces, and Films. 1995;13:2624-32.

https://doi.org/10.1116/1.579461

24. Nakayama Y, Yamamuro T, Kotoura Y, Oka M. In vivo measurement of anodic polarization of orthopaedic implant alloys: comparative study of in vivo and in vitro experiments. Biomaterials. 1989;10:420-24. https://doi.org/10.1016/0142-9612(89)90134-8

25. Köster R, Vieluf D, Kiehn M, Sommerauer M, Kähler J,
Baldus S, et al. Nickel and molybdenum contact allergies in patients with coronary in-stent restenosis. The Lancet. 2000;356(9245):1895-97. https://doi.org/10.1016/S0140-6736(00)03262-1

26. Ryhänen J, Niemi E, Serlo W, Niemelä E, Sandvik P, Pernu H, et al. Biocompatibility of nickel?titanium shape memory metal and its corrosion behavior in human cell cultures. Journal of Biomedical Materials Research: An Official Journal of The Society for Biomaterials and Japan Soci Biomater. 1997;35:451-57.

https://doi.org/10.1002/(SICI)1097-4636(19970615)35:4<451::AIDJBM5>3.0.CO;2-G

27. Guyuron B, Lasa JC. Reaction to stainless steel wire following orthognathic surgery. Plast Reconstru Surg. 1992;89:540-42. https://doi.org/10.1097/00006534-199203000-00025

28. Huang HH. Surface characterizations and corrosion resistance of nickel-titanium orthodontic archwires in artificial saliva of various degrees of acidity. Journal of Biomedical Materials Research Part A: An Official Journal of The Society for Biomaterials, Japan Soci Biomater, Australian Soci Biomater Korean Soci for Biomater. 2005;74:629-39.

https://doi.org/10.1002/jbm.a.30340 